\title{
POSIÇÃO DA ASSOCIAÇÃO BRASILEIRA DE ENFERMAGEM EM RELAÇÃO AO PREPARO DO PESSOAL DE ENFERMAGEM NO PAÍS
}

\author{
Amália C. de Carvalho
}

O assunto da palestra de hoje atual e oportuno por constituir parte de documento que será apresentado à Assembléia de Delegados no próximo Congresso Brasileiro de Enfermagem deve de fato preocupar as enfermeiras e principalmente àquelas que se dedicam ao ensino em qualquer dos níveis de enfermagem. E natural, e isto acontece em todos os ramos da educação, que os que se dedicam à formação de novos profissionais procurem associar-se de alguma maneira, a fim de possibilitar estudos ou discussões dos problemas curriculares e de metodologia de ensino. E, possivelmente, muitas das senhoras já se perguntaram porque não criar uma associação de professoras de estudos de enfermagem, ou uma associação de escolas de enfermagem, a exemplo das congêneres existentes no próprio campo da saúde, criadas para tratar especificamente dos problemas da educação médica e para-médica, como são a Associação Brasileira de Escolas Médicas - ABEM, Associação Brasileira de Ensino Odontológico - ABENO, Associação Brasileira de Ensino de Farmácia e Bioquímica - ABENFARBIO e a Associação de Ensino de Veterinária - ABENVET.

A resposta é simples e constitue o objeto das nossas considerações de hoje - a Associação Brasileira de Enfermagem - ABEn exerce e sempre exerceu as funções e as atividades que caracterizam uma entidade de caráter cultural e científico, destinada a estudar e a resolver os problemas educacionais relativos a seu campo de ação. E essas funções estão explícitas em dois dos objetivos da ABEn.

(*) Presidente da Associação Brasileira de Enfermagenz. Palestra proferida para o grupo de trabalho do Currículo do Curso Intensivo de Auxiliar de Enfermagem. Rio, maio de 1970. 
IV - pugnar pelo desenvolvimento da enfermagem em todos os seus ramos;

$\mathrm{V}$ - trabalhar pelo ensino e formação do pessoal de enfermagem e pela conservação do alto padrão de ética dos membros da classe.

A fim de alcançar esses objetivos, a ABEn está estruturada de tal forma que as atividades das suas Comissões Permanentes completam-se, de maneira a fazer convergir seus interesses e competências para os assuntos relacionados com o problemas educacionais; e a possibilidade que seus estatutos abrem à criação de comissões especiais destinadas ao estudo de assuntos de interêsse imediato, muitas vezes não previstos, é outro fator importante no desenvolvimento de suas atividades educacionais.

Um breve resumo das principais funções das Comissões Permanentes poderá concorrer para comprovar a grande preocupação da ABEn, pelos assuntos relacionados com a fomação do pessoal de enfermagem e com o desenvolvimento e aperfeiçoamento dos profissionais já em exercício. Assim, de acordo com o Regulamento dos Estatutos da ABEn, compete à Comissão de Assistência de Enfermagem, entre outras atividades, "incentivar as Seções a desenvolv€̣rem programas de atualização e de educação em serviço para o pessoal de enfermagem"; a Comissão de Documentação e Estudos tem, como uma de suas atribuições, a incumbência de coletar e divulgar dados sobre as escolas e cursos de enfermagem existentes no País"; à comissão de Educação, especificamente, estão afetas às seguintes atribuições:

“1. estudar os problemas relacionados com o ensino nos diferentes niveis de enfermagem e com a seleção e preparo do corpo docente;

2. atender às solicitações das escolas e dos cursos de enfermagem, referentes à elaboração de regimentos e à seleção dos campos de prática;

3. promover reunioes de diretores e professores, de âmbito nacional e regional, para o estudo de assuntos relaciondos ao ensino de enfermagem, em seus diferentes níveis;

4. manter entrosamento com as Seções no que se refere aos assuntos de educação em enfermagem;

5. manter-se vigilante em tudo que diz respeito à legislação do ensino de enfermagem. 
As Comissões de Legislação e da Revista Brasileira de Enfermagem, completam o quadro, cada uma no seu campo de ação, mantendo-se vigilante, a primeira, em relação a projetos de lei, decretos federais, e outros dispositivos relativos ao ensino de enfermagem, em tramitação pelas casas do Congresso, "preparando subsídios para documentar o ponto de vista da ABEn"; e a segunda, divulgando "artigos de interesse da classe", e que incluem matéria pedagógica de alto valor educativo.

Vejamos agora como a ABEn implementa essas disposições regimentais e estatutárias, e para tanto façamos um retrospecto da vida associativa das enfermeiras desde a criação da Associação Brasileira de Enfermeiras Diplomadas - ABED, em 1926. Apesar de possuirmos pouca informação sobre suas atividades iniciais, uma coisa é absolutamente certa - foi fundada pelas ex-alunas e pelas docentes da Escola de Enfermeiras Ana Neri, o que já é uma evidência de sua possível preocupação com os assuntos relacionados com o ensino de enfermagem. A criação em 1932, da Revista "Anais de Enfermagem", hoje Revista Brasileira de Enfermagem - RBEn, constitue também fator de importância na difusão de conhecimentos e das atividades do então reduzido grupo de educadoras de enfermagem.

Na fase de reestruturação da Revista, em 1946, aparecem artigos de relevância, oferecendo sugestões aos poderes públicos e estabelecendo diretrizes para a organizazção e o funcionamento de escolas de enfermagem.

Em 1946, o n..$^{\circ} 18$ da Revista dava à publicidade um artigo de Haydée G. Dourado intitulado “Organização de Escolas de Enfermagem no Brasil", que continha os mais modernos conceitos sobre a formação de enfermeiros e que reivindicava a integração das escolas dentiro do Sistema Educacional do País (só conseguido em 1961 com a Lei de Diretrizes e Bases da Educação). O n. ${ }^{\circ} 19$ trazia a colaboração de Edith Fraenkel no campo da inspeção de escolas de enfermagem resultado já de uma reunião de diretoras, realizada por iniciativa da ABEn. O n. ${ }^{\circ} 21$ apresentava o resultado da reestruturação da Associação, quando foi criada a Divisão de Educação, destinada a tratar especificamente de todos os assuntos relacionados com o ensino. $\mathrm{E}$ daí por diante não houve um único número da Revista Brasileira de Enfermagem que não tenha trazido artigos ou recomendações no campo da educação.

De importância capital, porém, foi a instituição dos congressos de enfermagem, anuais, quando, ao lado dos assuntos de interesse geral nos campos da enfermagem hospitalar e de saúde pública, eram trazidos para a apreciação e discussão em plenário, os pro- 
blemas educacionais de maior repercussão na época. Assim é que no 1. Congresso Brasileiro de Enfermagem, realizado em São Paulo de 17 a 22 de março de 1947, o assunto palpitante foi o relacionado com a formação do Auxiliar de Enfermagem, em virtude de já existir um curso com esse objetivo específico funcionando na Escola de Enfermeiras Ana Neri desde 1940, criado por D. Laís Neto dos Reys.

O trabalho apresentado pela insígne líder da enfermagem brasileira, d. Rosaly Taborda, demonstra a preocupação da classe e o grande interesse de todos pelo tema. Ao relêr, hoje, as conclusões que ela apresentou para discussão, tem-se a impressão de que o Congresso realizou-se há pouco tempo. Vejamos o que defendia $d$. Rosaly em relação ao preparo do Auxiliar de Enfermagem:

1. Todo o hospital geral que disponha de enfermeiras diplomadas, 3 pelo menos, deve abrir cursos para auxiliares, em turmas de 20 a 25; a formação do auxiliar de enfermagem deve ser levada a efeito, portanto, no hospital e não em escolas de enfermagem;

2. A duração do curso deve ser de 8 meses letivos, com uma carga horária de 1017 horas, sendo 153 horas para teoria e 864 para a prática; e para um grupo com instrução mínima de curso primário completo;

3. O corpo docente deve ser constituído exclusivamente por enfermeiras.

A ênfase dada pela relatora à formação do auxiliar no hospital é muito compreensível - temia, e seus temores foram confirmados em muitas instâncias, que a utilização dos mesmos docentes para ambos os cursos, de enfermagem e de auxiliar, poderia transformar esse último em uma miniatura do primeiro, com tendências à academicidade e à fuga ao campo de prática. Hoje fazemos a mesma pregação, utilizando apenas uma tônica diferente. E quando afirmamos que o curso de auxiliar de enfermagem deve ser essencialmente prático, e que não se aprende a cuidar dos doentes em salas de aula, mas sim junto do paciente, cuidando dele sơb a orientação de uma profissional mais experimentada, estamos dizendo quase a mesma coisa que D. Rosaly Taborda, apenas mudamos um pouco as palavras para facilitar a flexibilidade na localização do curso; dentro ou fora do hospital, pouco importa o essencial é que a enfermagem seja ensinada junto ao doente; também, é essencial que o aluno aprenda fazendo, a fim de tornar-se um profissional hábil e rápido na execução das atividades que lhe são afetas. 
A idéia do Curso Intensivo também não é nova. Muito recente, porém, é a exigência do $10^{\circ}$ ciclo ginasial, como requisito para 0 Curso Intensivo de Auxiliar de Enfermagem.

No Congresso, realizado no Rio em 1948, foi a voz do Doutor Marcolino Candau, então Superintendente do Serviço Especial de Saúde Pública - SESP, que se levantou para defender os mesmos pontos de vista e para alertar as enfermeiras sobre a inadequacidade da utilização do mesmo corpo docente para os dois cursos: enfatizava a importância do aproveitamento dos docentes das Escolas de Enfermagem para o aperfeiçoamento das demais enfermeiras em ambos os campos, hospitalar e de saúde pública, e preconizava a formação dos Auxiliares de Enfermagem pelos hospitais gerais.

De 1947 até o presente, não houve um só Congresso Brasileiro de enfermagem em que temas educacionais não tivessem sido abordados e discutidos. As resoluções e recomendações dos 21 congressos já realizados atestam esse fato. $\mathbf{E}$ acreditamos não exagerar quando afìrmamos que os congressos da Associação Brasileira de Enfermagem e a publicação da Revista Brasileira de Enfermagem constituiram e ainda constituem os fatôres mais importantes do progresso rápido da profissão no País. Na realidade, tudo o que se fêz, tudo o que se conseguiu de benefícios para a classe, para o ensino, para o aperfeiçoamento da assistência de enfermagem, foi feito e conseguido através da Associação.

Para não nos estendermos demasiado nesse ponto, citaremos apenas a realização da $A B E n$ que se tornou um marco no desenvolvimento da Enfermagem Brasileira - o levantamento de Recursos e Necessidades de Enfermagem no País; o estudo das condições das escolas de enfermagem e dos cursos de auxiliares de enfermagem, retratou umal situação desoladora, para a qual se chamou a atenção das entidades educacionais do País e do próprio corpo docente das escolas. As recomendações do levantamento serviram de orientação e diretriz para as entidades mantenedoras desses dois cursos, determinando o fechamento de alguns, a melhoria de muitos, e a criação de outros sob condições mais favoráveis do ponto de vista pedagógico.

E qual a posição atual da ABEn em relação ao preparo do pessoal de enfermagem? Do ponto de vista da diretoria, os objetivos citados no início desta palestra continuam válidos, com nítida tendência para ampliar as responsabilidades da Comissão de Educação que deverá constituir-se de sub-comissões que tratem dos problemas educacionais dos 3 níveis de ensino de enfermagem. Considerando, porém, que muito pouco poderá ser realizado, em âmbito nacional, em favor dos cursos técnico e de auxiliar, porque a maioria deles per- 
tence ao sistema estadual de ensino, a Comissão de Educação deverá orientar e oferecer diretrizes para as Seções Estaduais no sentido de que cada uma, em seu próprio Estado, constitua também, a sua Comissão de Educação, com objetivos mais amplos que os atuais, e que incluam:

1. Assistência e assessoria aos cursos técnicos e de auxiliar de enfermagem, quando solicitada;

2. Promoção de reuniões de diretoras e de professôras desses cursos para o estudo de assuntos relacionados com o desenvolvimento do currículo;

3. Promoção de encontros, jornadas, seminários regionais e cursos de atualização ou de extensão, que favoreçam o desenvolvimento do corpo docente dessas escolas;

4. Vigilância junto aos Conselhos Estaduais de Educação a fim de prevenir resoluções que possam prejudicar o ensino da parte profissional dos programas, e para assessorar e apresentar subsídios, quando solicitada.

De uma maneira geral, a diretoria da ABEn e sua Comissão de Educação têm-se mantido vigilantes e atentas junto ao Conselho Federal de Educação, apresentando sugestões e subsídios toda vez que um assunto relacionado com o ensino de enfermagem, em qualquer dos 3 níveis esteja sendo estudado e considerado. Como exemplos muito atuais, podemos citar as sugestões encaminhadas ao Conselho Federal de Educação com relação ao Currículo Mínimo do curso de enfermagem, e a solicitação da mudança na portaria n. ${ }^{\circ} 106 / 65$, para incluir a possibilidade dos Cursos Intensivos de Auxiliar de Enfermagem. Nem sempre as nossas sugestões e os nossos pedidos recebem o tratamento que julgamos merecerem. E o parecer n. 75/70 da Câmara do Ensino Primário e Médio, aprovado em 30 de janeiro do ano corrente, é uma prova disso; a nossa solicitação não foi atendida e ao problema foi dada uma solução que poderá acarretar novas preocupações, desta vez relacionadas com o exercício e o nível salarial das duas categorias, auxiliar de enfermagem e técnico de enfermagem. Oxalá, isto não ocorra!

No momento, será impossível apresentar a política educacional da ABEn, uma vez que o documento que a define ainda não foi discutido e aceito pela Assembléia de Delegados. Será possível, no entretanto, expôr as tendêneias dessa política, que poderá ser resumida em alguns pontos essenciais, com relação: 
I - ao aperfeiçoamento dos enfermeiros

1) incentivar a criação de cursos de pós-graduação nas Universidades que estiverem em condições de oferecê-los em nível de mestrado;

2) incentivatr as enfermeiras a seguirem a carreira docente, alertando-as sobre a inconveniência e o perigo da improvisação no magistério;

3) incentivar a criação de novos cursos de especialização, destinados a preparar especialistas nos diversos ramos da enfermagem, nos campos curativo e preventivo.

II - aos cursos de graduação:

1) incentivar a criação de novos cursos, integrados em Unıversidades oficiais ou particulares, em locais que apresentam condições econômicas e sócio-econômicas adequadas, que facilitem: o recrutamento de candidatos, a seleção e o desenvolvimento do corpo docente, e a seleção e o aperfeiçoamento dos campos de prática;

2) incentivar as escolas isoladas (13 atualmente ou $38 \%$ das existentes no País) a integrarem-se ou agregarem-se a Universidades oficiais ou particulares, a fim de se beneficiarem das facilidades pedagógicas oferecidas pelas Universidades;

3) continuar a luta por um currículo adequado, com duração mínima de, pelo menos, 1 ano para o curso básico e 2 anos e meio para o curso profissional;

4) prestar assistência às escolas que a solicitarem, oferecendo assessoria em assuntos administrativos e pedagógicos;

5) colaborar no desenvolvimento do corpo docente; incentivando a realização e participando em encontros, jornadas e seminários, destinados ao estudo e à discussão de assuntos relacionados com 0 currículo do Curso de Graduação;

6) manter no temário dos congressos anuais os assuntos de interesse das educadoras.

III - aos cursos Técnicos ou Colegiais:

Nesse campo a posição da ABEn é de expectativa. A sua característica de curso experimental não favorece uma tomada de 
posição sobre o assunto. O País necessita dessa e de qualquer outra categoria de pessoal de enfermagem, não há dúvida sobre este ponto. O que ainda não está muito definido, é o tipo de formação profissional que a técnico deve receber, onde deve ser dada e por quem.

O que aconteceu há alguns anos com as escolas de enfermagem, está ocorrendo agora com os Cursos Colegiais - proliferação desdrdenada com a preocupação com a determinação dos objetivos do curso, com o planejamento do programa profissional ou com a seleção de professôras-enfermeiras competentes.

Agrava ainda mais a situação o fato de enfermeiras colaborarem com os colégios interessados na criação do curso técnico, sem para isso estarem devidamente preparadas. O resultado será desastroso, certamente. Por isso, a ABEn pretende:

1) alertalr os Conselhos Estaduais de Educação sobre o perigo dessa proliferação dos cursos técnicos em locais sem as condições mínimas indispensáveis para a sua manutenção;

2) oferecer aos Conselhos Estaduais de Educação, por meio de Seções Estaduais, subsídios para a determinação do currículo desses Cursos, sugerindo meios para a sua fiscaliização por profissionais de enfermagem;

3) incentivar a promoção de reuniões regionais para a discussão dos problemas relacionados com a formação dos técnicos de enfermagem;

4) oferecer assessoramento para as entidades que tenham condições materiais e humanas, e que desejem criar os cursos técnicos;

5) incentivar a promoção de cursos de pequena duração sobre planejamento e metodologia do ensino, colaborando dessa maneira para o aperfeiçoamento do corpo docente;

6) continuar lutando para que a direção desses cursos pertença exclusivamente aos enfermeiros, assim como a ministração das materias profissionais e o ensino e a orientação dos estudantes no campo de prática.

IV - aos cursos de Auxiliar de Enfermagem:

1) incentivar a criação desses cursos, em qualquer de suas modalidades, nos locais que apresentem recursos materiais e humanos adequados;

2) incentivalr ou promover a realização de cursos de planejamento e metodologia do ensino para as professôras; colaborar na 
promoção de encontros, seminários e reuniões regionais para a discussão dos problemas comuns;

3) promover gestões junto às autoridades educacionais, em âmbito federal e estadual, a fim de conseguir a fiscalização dos cursos de auxiliar de enfermagem pelas próprias enfermeiras.

Com relação ao aperfeiçoamento do pessoal de enfermagem, em geral, a ABEn tem prestigiado sempre e continuará prestigiando, as realizações das Seções Estaduais no campo educacional, com a promoção de cursos de atualização ou de extensão para atendentes, auxiliares de enfermagem e enfermeiros. Esta atividade é considerada essencial para que a seção possa alcançar seus objetivos e cumprir com o seu papel de incentivadora de mudanças na comunidade.

No campo da literatura profissional, ainda que contando com escassos recursos, a ABEn propõe-se a continuar a publicação de livros ou folhetos de enfermagem, com o propósito de colaborar no desenvolvimento desse tipo de literatura, tão carente no País, e de cooperar com as escolas que lutam com sérias dificuldades nesse campo. 